\title{
A QUALIDADE DO ENSINO NA LEGISLAÇÃO E A FORMAÇÃO DE CONCEITOS: BASE PARA A APRENDIZAGEM HUMANA SEGUNDO DAVYDOV ${ }^{1}$
}

\section{THE QUALITY OF EDUCATION IN LAW AND CONCEPTS OF TRAINING BASE FOR HUMAN LEARNING SECOND DAVYDOV}

\author{
Valdivina Alves Ferreira ${ }^{2}$
}

\begin{abstract}
Resumo: O objetivo deste texto é apresentar uma discussão acerca do processo de formação e apropriação dos conhecimentos na forma de conceitos e sua relevância para a aprendizagem e o desenvolvimento do aluno na escola, numa perspectiva Davydoviana. Para Davydov (1988), as bases para a tese sobre a formação de conceitos implicam em compreender os conceitos de atividade humana, conceitos empíricos e pensamento empírico, conceitos teóricos e pensamento teórico e, finalmente a estruturação da atividade de ensino e aprendizagem para a formação de conceitos teóricos. O texto apresenta a discussão nessa sequência. Este trabalho é uma pesquisa bibliográfica e documental cujos resultados indicam que as contribuições de Davydov são efetivas e que sua proposta teórica poderia ser melhor utilizada para fazer avançar a qualidade da educação proferida nos documentos oficiais.
\end{abstract}

Palavras-chave: formação de conceitos. Conceitos empíricos. Conceitos teóricos.

Abstract: The objective of this paper is to present a discussion about the process of training and acquisition of knowledge in the form of concepts and their relevance to the learning and development of students in school, a Davydoviana perspective. To Davydov, the basis for the thesis on the formation of concepts imply understand the concepts of human activity, empirical concepts and empirical thinking, theoretical concepts and theoretical thinking and finally the structuring of teaching and learning activity for the formation of theoretical concepts . The paper presents the discussion that sequence. This paper is a literature review and the partial results indicate that contributions from Davydov are effective and that their theoretical proposal could be better used to advance the quality of education delivered in official documents.

Key words: concept formation. Empirical concepts. Theoretical concepts.

\section{Introdução}

A legislação educacional brasileira, mais especificamente a Constituição Federal (CF) em seu art. 205 garante "a educação, direito de todos e dever do Estado e da família, [...], visando ao pleno desenvolvimento da pessoa, seu preparo para o exercício da cidadania [...]." (BRASIL, 1988) e a Lei de Diretrizes e Bases da Educação Nacional (LDB), no 9394/96 prescreve em seu texto o direito à educação de qualidade. Em seu Art. $4^{\circ}$ ordena que "O dever do Estado com educação escolar pública será efetivado mediante a garantia de: [...] IX padrões mínimos de qualidade de ensino" e em seu Art. 13 apresenta como atribuição dos docentes em seu inciso III "zelar pela aprendizagem dos alunos" (BRASIL, 1996). Ora, o texto prescritivo da legislação assinala a educação de qualidade como direito e ainda

\footnotetext{
1 O conteúdo deste artigo decorre da pesquisa para a tese de doutorado intitulada "A FORMAÇÃO DE CONCEITOS MATEMÁTICOS NOS ANOS INICIAIS: COMO PROFESSORES PENSAM E ATUAM COM CONCEITOS", defendida no Programa de Pós-Graduação em Educação da Pontifícia Universidade Católica de Goiás (PUC Goiás), em 2013.

${ }^{2}$ Docente do Programa de Pós-Graduação em Educação - Mestrado e Doutorado - Universidade Católica Dom Bosco - UCDB.
} 
estabelece os padrões mínimos de qualidade a serem observados além de apontar o professor como o principal fomentador da materialização desse direito.

Entendendo o professor como principal articulador das ações que vão ao encontro da aprendizagem dos alunos nos bancos escolares, torna-se necessário empreender estudos que viabilizem uma discussão sobre o processo de aprendizagem desses alunos, tendo em vista a qualidade que a legislação aponta e que efetivamente é defendida por pesquisadores que tratam sobre o ensino e a aprendizagem escolar. Davydov (1988) é um dos pesquisadores russos que deu continuidade as pesquisas realizadas por Vygotky e que se dedicou ao importante problema que envolve as relações entre ensino e aprendizagem, formação de conceitos e desenvolvimento do pensamento do aluno. Em sua teoria, denominada de ensino desenvolvimental, entrelaça conceitos psicológicos e pedagógicos situados na perspectiva histórico-cultural tendo em vista a explicação de uma estrutura geral básica da atividade do ensino e da aprendizagem.

Interessa para o objetivo aqui proposto apresentar uma discussão acerca do processo de formação e apropriação dos conhecimentos na forma de conceitos e sua relevância para a aprendizagem e o desenvolvimento do aluno na escola. E ao, aqui optar por uma perspectiva Davydoviana de formação de conceitos implica compreender os conceitos de atividade humana; conceitos empíricos e pensamento empírico; conceitos teóricos e pensamento teórico e, finalmente a estruturação da atividade de ensino e aprendizagem para a formação de conceitos teóricos. O texto apresenta a discussão desses elementos. A partir da pesquisa bibliográfica e documental conclui-se que as contribuições de Davydov são efetivas e que sua proposta teórica poderia ser melhor utilizada para fazer avançar a qualidade da educação proferida nos documentos oficiais.

\section{O Processo de formação de conceitos na perspectiva Davydoviana}

$\mathrm{Na}$ direção da busca de entendimento sobre o processo de formação de conceitos fazse necessário compreender o conceito de atividade humana. Este conceito aparece na teoria de Davydov a partir da teoria da atividade formulada por Leontiev. Leontiev (1983, 1988) explica o desenvolvimento humano como processo de apropriação das riquezas espirituais (culturais e históricas) acumuladas pelo gênero humano, que se inicia quando a criança, por meio das inter-relações e da comunicação com os outros, vai desobjetivando para si os significados culturais dos objetos e, ao mesmo tempo, as ações que se realizam com esses objetos, atribuindo-lhes um sentido pessoal. Os significados atribuídos às coisas em contextos de relações sociais, imersos na cultura, uma vez apropriados, passam a fazer parte da atividade psíquica da criança como instrumentos (culturais, semióticos, mentais) para orientar sua ação enquanto sujeito no mundo, na realidade. Desse modo, a criança se desenvolve mediante um movimento dialético e contínuo de subjetivação e objetivação da realidade e, nesse movimento, constitui sua personalidade.

Leontiev (1983), fundamentando-se nas teses de Marx, investigou a estrutura e o funcionamento da atividade psicológica humana, distinguindo dois tipos: a atividade humana interna - que ocorre apenas no plano mental, por meio de ações psíquicas - e a externa - que consiste na ação humana com objetos, por meio de ações no plano material. Ambas estão intrinsecamente interligadas. De um modo geral, toda atividade inclui elementos de atividade externa e interna, de atividade prática e teórica, mental. No entanto, a atividade externa tem precedência sobre a interna, pois todos os tipos concretos de atividade humana surgem a partir das diversas necessidades humanas nas relações sociais (LEONTIEV, 1983, 1988). 
Freitas (2009) sintetiza a concepção de Leontiev sobre a estrutura geral da atividade humana, para o qual esta é o conjunto das suas relações reais com os objetos no mundo. $\mathrm{Na}$ atividade interna o ser humano não realiza ações com os objetos em si, e essas ações não são físicas ou corporais; ele realiza ações com as imagens dinâmicas do objeto (seu reflexo psíquico) por meio de ações mentais. Para Leontiev (1983), o traço mais característico da atividade psíquica humana é seu esforço deliberado para a transformação da sua realidade, que surge para atender ou resolver uma necessidade humana, para a qual deve ser buscado um objeto capaz de satisfazê-la. Assim, toda atividade humana é sempre caracterizada por sua orientação a um objeto com um propósito específico e existe em função daquilo que a motiva: seu objeto, e são esses motivos que dirigem essa atividade. A ação orientada ao objeto e com um objetivo é o meio pelo qual se pode satisfazer o motivo e alcançar o atendimento da necessidade. Para isso a ação se desdobra em várias operações. Ações e operações, por sua vez, são realizadas em circunstâncias específicas, em determinadas condições para sua execução, sem as quais não podem ser realizadas de forma a atingir o objetivo e satisfazer o motivo.

Dessa forma, a consciência humana é produto de relações sociais estabelecidas entre as pessoas e que se realizam somente mediante a atividade mental, psíquica. Nos processos surgidos das relações sociais entre pessoas ocorre a substituição dos objetos materiais por suas formas subjetivas, mentais, como imagens ou reflexos, na forma de consciência (LEONTIEV, 1983).

Lompscher (1999) analisa que, enquanto para Leontiev a atividade é essencialmente objetal, porque surge como relação real do sujeito com os objetos materiais no mundo, Vygotsky ressalta a importância da mediação semiótica na atividade psíquica. Contudo, de acordo com Lompscher, ambos compreendem a aprendizagem como um processo de apropriação cultural e científica, sendo o meio de promoção do desenvolvimento mental do aluno.

Já Davydov (1997) aponta que Vygotsky (1998), ao explicar o processo de formação de conceitos não chegou a alcançar a lógica dialética pois, embora tivesse consciência de que a análise dos conceitos científicos requer instrumentos da lógica dialética, não teve tempo para assimilá-los de modo suficiente em sua teorização. Tal empreendimento tornou-se um dos objetivos para os que se dedicaram a dar continuidade às ideias de Vygotsky como El'konin, Ilyénkov e outros, inclusive o próprio Davydov, que se dedicou à distinção entre pensamento cotidiano ou empírico, e pensamento científico, ou teórico, nos quais estão envolvidos também dois tipos fundamentalmente diferentes de generalização e de conceito.

De acordo com a crítica apresentada por Davydov (1997), a falta de um delineamento na explicação do conteúdo da generalização do pensamento por parte de Vygotsky (1998) denota a ausência das bases para a distinção entre os conceitos espontâneos e os científicos. Por isso, Vygotsky (1998) diferenciou um conceito do outro atribuindo às condições de seu desenvolvimento a falta de sistematização para o primeiro e a existência de determinada sistematização para o segundo. Assim a diferenciação entre ambos foi atribuída não ao plano do seu conteúdo objetivo e sim ao modo e ao percurso da assimilação. Davydov procurou avançar essa distinção apontando os dois tipos de pensamento humano, o empírico e o teórico, caracterizados por diferentes tipos de generalização e de conceito. A seguir, procura-se fazer essa distinção de Davydov (1997) em relação à Vygotsky (1998), sendo possível verificar que Davydov não distingue esses dois conceitos apenas pelo grau de sistematização, mas principalmente pelos diferentes tipos e formas de pensamento conexas a eles. 


\section{Notandum 42 set-dez 2016 - CEMOrOC - Feusp / IJI-Univ. do Porto \\ DOI: http://dx.doi.org/10.4025/notandum.42.7}

Ao fazer esta distinção entre os estudos apontados por Vygotsky e Davydov torna-se salutar apontar a importância do conceito de generalização. Antes a generalização foi descrita como um processo privilegiado na formação de conceitos de acordo com a teoria de Vygotsky (1998). Para Davydov (1988), o termo generalização é frequente na literatura psicológica, didática e sobre métodos de ensino. Todavia, a generalização não é considerada uma via fundamental da formação de conceitos, que deve ser a principal finalidade do ensino na escola.

Para o autor, é comum a generalização ser compreendida como o processo pelo qual os alunos analisam e comparam entre si os objetos apresentados pelo professor, com semelhanças entre si, devendo distingui-los e identificar suas qualidades comuns. Assim, a definição do conceito é a enumeração das qualidades gerais para os objetos. $\mathrm{O}$ aspecto geral torna-se algo que se repete, invariável e, portanto, definidor das propriedades dos objetos. Para realizar a generalização, como abstração mental do objeto, a criança deve identificar certa qualidade comum dos objetos, invariante. Essa qualidade é designada por uma palavra, que fixa o conhecimento abstrato. Esse movimento de apreensão do objeto e de formação de seu conceito parte do aspecto sensorial do objeto para chegar à sua percepção abstrata por um processo de generalização empírica.

De acordo com Davydov (1988), a importância desse processo de generalização possibilita aos alunos as ações mentais de sistematização e de classificação dos objetos, uma das tarefas centrais do ensino escolar. Por meio desse tipo de ação mental os alunos classificam plantas, palavras, figuras geométricas, etc., e tornam-se capazes de situá-los em uma hierarquia de generalizações de acordo com suas propriedades. Ou seja, esse tipo de generalização conceitual permite ao ser humano enxergar o que é comum a toda uma classe de objetos em cada objeto concreto. Esse caminho de generalização e formação do conceito ocorre da seguinte forma:

No processo de ensino, a palavra do professor organiza a observação dos alunos, indicando com exatidão o objeto da observação, orienta a análise para diferenciar os aspectos essenciais dos fenômenos daqueles que não o são e, finalmente, a palavra-termo, sendo associada aos traços distinguidos, comuns para toda uma série de fenômenos, se converte em seu conceito generalizador. (DAVYDOV 1988, p. 60-61)

Comum nas disciplinas escolares, esse caminho conduz os alunos às generalizações a partir da observação do objeto, em sua dimensão visual, sensorial, direta. Trata-se de um caminho de pensamento correspondente à lógica formal, que serve de base para a psicologia associacionista subjetivo-empírica, que se resume à separação de processos de pensamento isolados: a abstração e a generalização, a comparação e a classificação. Por essa lógica, o geral é compreendido apenas como semelhante ou igual em uma classe de objetos e o essencial como o traço que distingue essa classe de objetos. Desse modo, há uma transição da percepção do objeto à sua representação e depois ao seu conceito fixado na palavra.

Davydov (1988) apresenta à teoria lógico-formal do pensamento uma crítica fundamental: ela leva apenas à formação de conceitos empíricos. Embora seja a lógica utilizada amplamente na conceituação de objetos científicos das ciências naturais (plantas, algas, insetos, peixes, aves, minerais, rochas, etc.), essas abstrações e generalizações não permitem ao pensamento captar a especificidade dos conceitos científicos teóricos, que 


\section{Notandum 42 set-dez 2016 - CEMOrOC - Feusp / IJI-Univ. do Porto \\ DOI: http://dx.doi.org/10.4025/notandum.42.7}

possibilitam apreender um objeto ou fenômeno por sua essência, e não meramente por seus traços sensoriais e aparentes. Nessa crítica, Davydov recorre a uma passagem de Marx:

Mas o economista vulgar crê que faz uma grande descoberta quando, em lugar de revelar a conexão interna das coisas, proclama orgulhosamente que, nos fenômenos, as coisas têm uma aparência completamente distinta. De fato, se orgulha de posicionar-se ante a aparência e toma esta como última palavra. Que falta pode fazer então a ciência? (MARX apud DAVYDOV, 1988, p. 61-62)

Ainda utilizando-se dessa crítica, Davydov aponta que a adesão à lógica formal e ao pensamento empírico refletiu, nas escolas, numa concepção didática de organização do ensino de um objeto ou fenômeno indo do seu aspecto particular ao seu aspecto geral. Vai-se da comparação de objetos particulares a uma generalização e, por fim, ao conceito, por um movimento de ascensão do sensorial-concreto ao mental-abstrato, sendo essa abstração expressa na palavra. É por isso que nessa lógica "empírico" significa sensorial, palpável, concreto, e teórico significa abstrato, verbal, geral. Consequentemente, quanto maior o nível de generalização mais teórico será o pensamento. Então, equivocadamente, teórico passa a ser sinônimo de verbal.

Remetendo-se à crítica ao ensino escolar da matemática, Davydov (1988, p. 66) cita a crítica de A. Kolmogórov, para quem a separação dos conceitos matemáticos de sua origem leva a uma deficiência do ensino: "[n]os diferentes degraus do ensino se manifesta, com distinto grau de audácia e invariavelmente, uma mesma tendência: terminar o antes possível com a introdução aos números e falar somente dos números e suas correlações".

Acrescentando sua própria crítica, afirma Davydov (1988, p. 66-67):

O divórcio entre o ensino dos conceitos e o exame das condições nas quais se originam se deriva legitimamente da teoria da generalização empírica, segundo a qual o conteúdo dos conceitos é idêntico ao que inicialmente se dá na percepção, Nela se examina somente a transformação da forma subjetiva deste conteúdo: a passagem de sua percepção imediata ao "subentendido" nas descrições verbais. Nesta teoria está ausente o problema da origem do conteúdo dos conceitos. Em relação ao método de ensino das matemáticas elementares isto implica, por exemplo, que o professor proponha às crianças, para realizar diferentes operações, um conjunto de unidades já separadas, representadas em forma de "figuras numéricas". Como e de que premissas não numéricas surgiram, como se formou historicamente o conteúdo do conceito de número, tudo isto fica fora de exame. A criança começa a familiarizar-se imediatamente com os resultados do processo que teve lugar na história do conhecimento.

$\mathrm{Na}$ generalização conceitual empírica as propriedades externas dos objetos, sua aparência, são tomadas como se fosse sua essência. Esse é o limite do pensamento empírico, cuja formação é proporcionada pela generalização e pelos conceitos empíricos. Para Davydov, a formação desse pensamento no processo de ensino tem sua importância e deve ser 


\section{Notandum 42 set-dez 2016 - CEMOrOC - Feusp / IJI-Univ. do Porto \\ DOI: http://dx.doi.org/10.4025/notandum.42.7}

assegurado não como o tipo dominante de pensamento, mas apenas como um degrau para o desenvolvimento do pensamento teórico.

Nesse degrau para o desenvolvimento do pensamento teórico implica apropriar-se do pensamento racional dialético. O pensamento racional dialético, ao buscar no objeto a unidade na diversidade, vai além dos limites da lógica formal e do pensamento empírico e tem como princípio evidenciar o movimento pelo qual ocorrem as passagens entre os diferentes aspectos de um objeto.

Davydov e os pedagogos e psicólogos russos de sua equipe colocaram como um problema a ser respondido cientificamente a aplicação dos princípios do pensamento dialético na organização da atividade de ensino para a formação de conceitos nos escolares. Seu objetivo era oferecer uma contribuição ao avanço do ensino escolar para além do pensamento empírico, alcançando a concretização do pensamento teórico. Ao enfatizar que o conceito de atividade foi introduzido na ciência contemporânea pela lógica dialética, Davydov (1988, p. 12) ressalta seu núcleo:

A razão pensante (a mente) exacerba a diversidade do diverso para o ponto de oposição. Somente as ideias diversas (díspares), elevadas a este nível, se tornam reciprocamente móveis e, dessa forma, podem ser entendidas em seu auto movimento e vitalidade internos. Falando do "núcleo da dialética," Lenin observou que "a dialética pode ser concisamente definida como a doutrina da unidade dos opostos".

É pelo procedimento de ascensão do abstrato ao concreto que é possível realizar a reprodução teórica do concreto real como unidade do diverso. Esse é o "o procedimento com a ajuda do qual o pensamento assimila o concreto, o reproduz como espiritualmente concreto" (MARX apud DAVYDOV, 1988, p. 82). Significa que no pensamento humano o objeto ou fenômeno concreto aparece como uma síntese resultante de seu trabalho mental, mas também como ponto de partida que serviu a essa atividade pensante. Inicialmente o objeto é captado sensorialmente, mas apenas uma etapa para ser captado e reproduzido idealmente em suas conexões internas universais é necessária, expressando-se o seu movimento em uma lógica conceitual. Novamente citando Marx, Davydov (1988, p. 82) escreve: "Por onde começar tal reprodução? De acordo com a dialética é necessário começar pelo abstrato. As definições abstratas conduzem à reprodução do concreto por meio do pensamento".

Para realizar esse movimento são necessárias abstrações do tipo teórico, não do tipo empírico, pois estas não alcançam a essência do objeto. A abstração pela qual começa o pensamento teórico tem como conteúdo a conexão historicamente simples do objeto (sua integralidade, universalidade). Ademais, as contradições dessa conexão devem refletir também sua essência:

Sendo um aspecto do concreto, isto é, tendo sua forma peculiar, esta conexão aparece, simultaneamente, como fundamento genético do todo (e neste sentido aparece como universal). Aqui se observa a unidade do singular (peculiar) e do universal, objetivamente existente, a conexão que mediatiza o processo de desenvolvimento do todo. (DAVYDOV, 1988, p. 82) 


\section{Notandum 42 set-dez 2016 - CEMOrOC - Feusp / IJI-Univ. do Porto \\ DOI: http://dx.doi.org/10.4025/notandum.42.7}

Para referir-se a essa abstração inicial o autor utiliza as denominações "célula" ou "abstração substantiva". Ainda, para melhor elucidar, questiona por que denominá-la abstração se ela na verdade é real e observável. Afirma, em seguida, que a resposta é a compreensão do conceito de abstrato empregado na lógica dialética:

O abstrato e o concreto são momentos do desmembramento do próprio objeto, da realidade mesma, refletida na consciência e por isso são derivados do processo da atividade mental. A confirmação da objetividade de ambos os momentos é a peculiaridade mais importante da dialética como lógica. (DAVYDOV, 1988, p. 83).

Então, a abstração substantiva aparece como objeto simples, não desenvolvido, homogêneo, que ainda não atingiu as necessárias diferenciações. Aqui ela é a abstração geneticamente inicial de um objeto em sua totalidade. Mas, em segundo lugar, a abstração substantiva pode ter a forma já desenvolvida do objeto, na qual ele perde suas distinções particulares. Assim, a abstração realiza-se como redução das particularidades do objeto à sua forma abstrata. Externamente ao pensamento humano, os objetos e fenômenos existem como singulares, particulares, concretos, desenvolvidos a partir de uma relação real, que contém um aspecto essencial, uma "célula". Nessa célula está sua natureza universal, base de todas as formas pelas quais o objeto aparece de maneira particular. Desenvolver essa compreensão é pensar o objeto em uma lógica dialética, exemplificada por Davydov na álgebra: "[...] Por exemplo, $a, b, c$, representam os números em geral, em forma geral, mas afinal são números inteiros, em contraposição aos números $a / b, b / c, c / b, c / a, b / a$ etc., os quais, entretanto, pressupõem estes números inteiros como elementos universais" (MARX apud DAVYDOV, 1988, p. 83-84).

Por consequência, particular e universal existem sempre na forma de relações e conexões mútuas de um objeto. "O universal existe só no individual e por meio do individual. Todo individual é (de um modo ou de outro) universal. Todo universal é (um fragmento, ou um aspecto, ou a essência de) o individual" (LENIN apud DAVYDOV, 1988, p. 83-84). Para acessar um objeto por essa forma de pensamento, isto é, partir de um fenômeno superficial, em sua imediatez, e chegar a compreendê-lo de forma mediada, em sua essência, são necessárias as ações de abstração, generalização e, por fim, expressão do objeto na forma de conceito. Chegar à essência do objeto é chegar à sua determinação universal. Como exemplo Davydov menciona o trabalho, explicando que todos os tipos particulares de trabalho humano reduzem-se ao trabalho humano universal, que contém a essência de todo trabalho.

O conteúdo específico do pensamento teórico é o objeto mediado. O ser humano entra em relação com o objeto da atividade prática e o reproduz de forma ideal, mental, pela atividade pensante, realizando com ele inúmeros experimentos mentais, os quais não se operam com representações dos objetos somente, como ocorre no pensamento empírico, mas sim com ações conceituais. A pessoa apropria-se de um conceito sobre um objeto quando é capaz de reproduzi-lo mentalmente, compreendendo e explicando a sua essência, expressando verbalmente seu conteúdo e as particularidades deste. Assim, verifica-se o caráter essencialmente mediado e simbólico do pensamento teórico:

Na produção espiritual, assim como na material, existem meios próprios para se reproduzir o objeto. Além disso, o homem utiliza uma "artimanha": 


\section{Notandum 42 set-dez 2016 - CEMOrOC - Feusp / IJI-Univ. do Porto \\ DOI: http://dx.doi.org/10.4025/notandum.42.7}

descobre e recria as propriedades dos objetos por meio de suas relações e conexões mútuas. Uma coisa se converte em meio para encarnar as propriedades de outras coisas, atuando como seu padrão e medida. $\mathrm{O}$ resultado desta encarnação pode ser representado, por exemplo, em uma escala de dureza ou em uma representação das formas do espaço. Aqui as propriedades da medida e do padrão não representam sua própria natureza senão a natureza de outras coisas; a medida e o padrão aparecem como seus símbolos. Os diferentes sistemas de símbolos (materiais e gráficos) podem converter-se em meios para estabelecer padrões e, com eles, idealizar os objetos materiais, em meios de transição destes ao plano mental. E. Iliénkov escreve: "A existência funcional do símbolo consiste em que ele... atua como meio, como instrumento para revelar a essência de outras coisas captadas sensorialmente, isto é, sua universalidade". A revelação e a expressão em símbolos da existência mediatizada das coisas, de sua universalidade, não é outra coisa senão a passagem à reprodução teórica da realidade. (DAVYDOV, 1988, p. 74)

Ao reproduzir mentalmente a essência do objeto o ser humano utiliza os símbolos (materiais, gráficos e mentais), que se convertem em meios para estabelecer padrões, e, com eles, idealizam objetos materiais, meio de transição destes ao plano mental. O símbolo atua como instrumento mediador na revelação da essência das coisas captadas sensorialmente pelas pessoas. Davydov (1928, p. 303) ilustra a tese do pensamento teórico, recorrendo ao exemplo de Spinoza para demonstrar o conceito de círculo:

Spinoza via a essência do círculo no ato de sua origem, de sua construção ("criação"). A definição do círculo deve expressar a causa da origem da coisa dada, o método de sua construção. O círculo segundo esta regra, [...] deve definir-se assim: é a figura escrita por qualquer linha, um de cujos extremos é fixo e o outro móvel. Aqui se indica o método para se obter quaisquer círculos infinitamente diversos.

Nesse caso, Spinoza explicitou verbalmente a idealização de um esquema de atividade que permite o detalhamento da construção e do procedimento de uma ação, utilizando nesse processo de formação o conceito de círculo, a partir de um instrumento relativamente simples: o compasso.

A essência do pensamento teórico consiste na compreensão das coisas por meio da análise das condições de sua origem e de seu desenvolvimento histórico. Em outras palavras, pelo procedimento de ascensão do abstrato ao concreto.

Os procedimentos de ascensão do abstrato ao concreto implicam em identificar a abstração inicial. A abstração inicial origina-se pela análise das relações particulares e nelas a identificação do aspecto que simultaneamente apresenta caráter de universalidade ou forma universal (a base genética do todo, a célula). Depois se estuda essa forma universal ou a essência, que se manifesta em todas as formas particulares. Isso corresponde a essa célula ou base genética e deve ser o fundamento para deduzir o sistema de conexões mediante as quais se desenvolve a essência do objeto e analisar por que essa essência se apresenta e se manifesta no objeto concreto. Portanto, realiza-se um processo de recriação do concreto por meio de 


\section{Notandum 42 set-dez 2016 - CEMOrOC - Feusp / IJI-Univ. do Porto \\ DOI: http://dx.doi.org/10.4025/notandum.42.7}

análise e síntese. Para ilustrar essa capacidade de síntese da mente humana, Davydov (1988, p. 85) novamente cita Iliénkov:

As determinações abstratas isoladas, cuja síntese fornece "o concreto no pensamento" formam-se no próprio curso da ascensão do abstrato ao concreto. Deste modo, o processo teórico que leva à obtenção do conhecimento concreto, em cada um de seus elos e no conjunto, é sempre ao mesmo tempo o processo de redução do concreto ao abstrato.

Assim, a natureza do pensamento teórico se expressa no movimento de redução e ascensão ao concreto, sendo este último o mais determinante, pois é por meio dele que são reveladas as contradições dentro da relação principal identificada na abstração inicial. Para a resolução dessas contradições o pensamento teórico apoia-se nos dados reais, parte do universal, mas este não coincide diretamente com as manifestações particulares e singulares da totalidade do objeto concreto, exigindo que se reconheçam os elos mediadores para a explicação dessas manifestações.

O pensamento teórico, como pensamento característico da ciência, possibilita ao sujeito a capacidade de ver o todo antes de ver suas partes e captá-lo primeiro, capacidade esta indispensável à reprodução teórica da realidade. Esse é um dos momentos essenciais do movimento do abstrato ao concreto do ponto de vista dialético. Em resumo, o pensamento teórico se realiza por meio de análise e síntese, como processos mutuamente dependentes e que formam uma unidade na solução de tarefas ou problemas cognitivos a serem resolvidos:

1) pela análise dos dados reais e sua generalização separa-se a abstração substantiva, que estabelece a essência do objeto concreto estudado e que se expressa no conceito de sua "célula"; 2) depois, pelo caminho da revelação das contradições nesta "célula" e da determinação do procedimento para sua solução prática, segue a ascensão a partir da essência abstrata e da relação universal não desmembrada, até a unidade dos aspectos diversos do todo em desenvolvimento, ao concreto. (DAVYDOV, 1988, p. 86)

Descrito o processo de ascensão do abstrato ao concreto, é de interesse caracterizar com maiores detalhes a generalização substantiva e o pensamento teórico como aspectos desse processo de ascensão. A generalização substantiva acompanha as relações do universal abstrato com o singular e particular. Por meio do conceito teórico, abstrato, já alcançado, analisam-se os fenômenos particulares, deduzindo-os da base universal. Em resumo, a generalização substantiva consiste em tomar os fenômenos particulares e reduzi-los a uma base única, universal, revelando a unidade na diversidade, compreendendo o movimento dialético de existência do universal no particular e vice-versa.

O conceito teórico (pensamento teórico) tem um conteúdo e uma forma, sendo o primeiro reflexo das relações entre universal e particular e o segundo o procedimento de dedução deste particular a partir do universal, ou seja, o procedimento de ascensão do abstrato ao concreto. A transformação, passagem, do objeto particular ao seu universal e desse universal ao particular, apenas é acessível pelo experimento mental com o objeto idealizado, ou seja, objeto concreto reproduzido pelo pensamento na forma ideal: 


\section{Notandum 42 set-dez 2016 - CEMOrOC - Feusp / IJI-Univ. do Porto DOI: http://dx.doi.org/10.4025/notandum.42.7}

No experimento mental que, a nosso ver, está intimamente vinculado aos conceitos teóricos, podem ser realizadas transformações dos objetos que não se podem efetuar por meio de ações práticas objetais. Se estas transformações descobrem no objeto novas propriedades, constituem justamente os resultados específicos do pensamento teórico que reflete a natureza interna da realidade. (DAVYDOV, 1988, p. 88)

Davydov utiliza o termo conhecimento para designar a unidade entre abstração, generalização e conceito, que ocorrem tanto no pensamento empírico como no teórico, mas com conteúdo e formas muito distintas. Da mesma maneira, se distinguem as tarefas para cada um desses tipos de pensamento: enquanto o pensamento empírico cataloga e classifica os objetos, o pensamento teórico reproduz a essência do objeto. Assim resume suas principais diferenças:

Quadro 01 - Comparação entre conhecimento empírico e teórico.

\begin{tabular}{|l|l|}
\hline Pensamento / conhecimento empírico & Pensamento / conhecimento teórico \\
\hline $\begin{array}{l}\text { São elaborados no processo de comparação dos } \\
\text { objetos, separando suas propriedades iguais, } \\
\text { comuns, produzindo representações sobre eles. }\end{array}$ & $\begin{array}{l}\text { São elaborados no processo de análise do papel } \\
\text { e da função de certa relação peculiar dentro do } \\
\text { sistema integral que, ao mesmo tempo, serve de } \\
\text { base genética inicial de todas as manifestações } \\
\text { do objeto. }\end{array}$ \\
\hline $\begin{array}{l}\text { No processo de comparação ocorre a separação } \\
\text { da propriedade geral do conjunto de objetos, que } \\
\text { é utilizada para relacionar objetos isolados a } \\
\text { uma classe determinada, independentemente dos } \\
\text { vínculos entre eles. }\end{array}$ & $\begin{array}{l}\text { No processo de análise descobre-se a relação } \\
\text { geneticamente inicial do sistema integral como } \\
\text { sua base universal ou essência. }\end{array}$ \\
\hline $\begin{array}{l}\text { Os conhecimentos empíricos apoiam-se nas } \\
\text { observações e por isso refletem nas suas } \\
\text { representações as propriedades externas dos } \\
\text { objetos. }\end{array}$ & $\begin{array}{l}\text { Os conhecimentos teóricos, por apoiarem-se na } \\
\text { transformação mental dos objetos, refletem suas } \\
\text { relações e conexões internas "saindo" dos } \\
\text { limites das representações. }\end{array}$ \\
\hline $\begin{array}{l}\text { A propriedade geral formal é separada como } \\
\text { algo pertencente à ordem das propriedades } \\
\text { particulares e singulares dos objetos. }\end{array}$ & $\begin{array}{l}\text { Determina-se o nexo da relação universal, real, } \\
\text { do sistema integral com suas diferentes } \\
\text { manifestações, o elo do universal com o } \\
\text { singular. }\end{array}$ \\
\hline $\begin{array}{l}\text { A concretização dos conhecimentos empíricos } \\
\text { consiste em selecionar ilustrações, exemplos, } \\
\text { que se encaixam na correspondente classe dos } \\
\text { objetos. }\end{array}$ & $\begin{array}{l}\text { A concretização dos conhecimentos teóricos } \\
\text { consiste na dedução e explicação das } \\
\text { manifestações particulares e singulares do } \\
\text { sistema integral a partir de seu fundamento } \\
\text { universal. }\end{array}$ \\
\hline $\begin{array}{l}\text { As palavras-termos são o meio indispensável } \\
\text { para expressar os conhecimentos empíricos. }\end{array}$ & $\begin{array}{l}\text { Os conhecimentos teóricos se expressam, } \\
\text { sobretudo, nos procedimentos mentais e, } \\
\text { posteriormente, com a ajuda de meios } \\
\text { simbólicos e semióticos, nas linguagens natural } \\
\text { e artificial. }\end{array}$ \\
\hline
\end{tabular}

Fonte: Dados elaborados pela autora com base em Davydov (1988). 


\section{Notandum 42 set-dez 2016 - CEMOrOC - Feusp / IJI-Univ. do Porto \\ DOI: http://dx.doi.org/10.4025/notandum.42.7}

O pensamento teórico, característico da lógica dialética, é o modo privilegiado de reflexão racional da ciência, mas também de todas as formas superiores de consciência social. Ele se realiza fundamentalmente no plano das ações mentais, isto é, como experimento mental com os objetos de conhecimento.

Considerando que a caracterização psicológica da solução teórica de uma tarefa feita por S. Rubinstein corresponde à compreensão lógica do pensamento teórico, Davydov (1988 p. 90) cita-o: "Resolver uma tarefa teoricamente quer dizer resolver não só para o caso particular dado, mas também para todos os casos semelhantes".

Por meio da abstração o ser humano identifica a relação inicial de certo sistema integral e, nessa ascensão mental, conserva a sua especificidade, identificando a máxima semelhança entre os objetos. Consiste, assim, em um processo que tem como princípio uma relação particular, subjetivada e individual.

O processo de generalização consiste no caminho para descobrir e acompanhar as inter-relações existentes entre o particular e o singular por meio da análise do todo e tem como objetivo captar o objeto em sua essência, nas suas relações, reduzindo os diversos fenômenos a uma base única, universal: a essência como genuína base interna de todas as modificações do objeto. O produto desse procedimento é o conhecimento sobre o objeto ou a aprendizagem. O conceito teórico aparece como unidade, a partir da redução da diversidade, ou seja: o "conceito teórico serve de procedimento para deduzir os fenômenos particulares e singulares de sua base universal", afirma Davydov (1988, p. 87).

O autor explica que a tarefa de nosso pensamento é organizar os dados captados a partir do concreto sensorial, na forma de conceito, reproduzindo as conexões internas do objeto, suas relações, identificando e apresentando o movimento desse objeto. As relações internas e externas, bem como suas contradições e sua trajetória histórica real constituem o movimento do objeto.

O pensamento teórico se constitui no processo de análise do papel e da função das relações existentes dentro de um todo observado. Sua origem tem como base a transformação mental dos objetos, refletindo suas conexões internas, e se caracteriza como uma ponte entre o universal e o singular. Davydov (1988, p. 89) afirma que a "concretização dos conhecimentos teóricos consiste na dedução e explicação das manifestações particulares e singulares do sistema integral a partir de seu fundamento universal". Nesse tipo de conhecimento, os procedimentos mentais, auxiliados pelos meios simbólicos, são os principais responsáveis por sua expressão.

Dessa forma, é importante assinalar a qualidade do ensino nessa perspectiva. E sobre a questão da qualidade, Saviani (2015) faz a seguinte observação em uma entrevista, ao ser questionado sobre o significado da qualidade do ensino: "se tomarmos a educação escolar como tendo o objetivo principal de permitir o ingresso na cultura letrada, via alfabetização, e a partir daí, o domínio dessa cultura, via apropriação dos conhecimentos sistematizados" [...], onde a "precondição para se atingir níveis melhores de qualidade de ensino é a preparação dos professores", pode-se afirmar que há qualidade no ensino. Nos documentos legais o direito e a qualidade à educação são preconizados com veemência. Na Constituição Federal no Capítulo III, Art. 205 está prescrito que a educação é "direito de todos e dever do Estado e da família [...], visando ao pleno desenvolvimento da pessoa, seu preparo para o exercício da cidadania [...]". Brasil (1988). A questão do pleno desenvolvimento da pessoa pressupõe uma educação de qualidade, uma vez que um dos princípios apontados pelo art. 206, no inciso VII desse documento é a garantia do padrão de qualidade no ensino. Outro documento oficial 


\section{Notandum 42 set-dez 2016 - CEMOrOC - Feusp / IJI-Univ. do Porto \\ DOI: http://dx.doi.org/10.4025/notandum.42.7}

importante que trata sobre a questão da qualidade é a LDB n 9394/96. Esta Lei estabelece as diretrizes e bases da educação nacional e prescreve em seu título III, ao tratar do direito à educação e do dever de educar, em seu art. $4^{\circ}$ afirma que

O dever do Estado com educação escolar pública será efetivado mediante a garantia de: [...] IX - padrões mínimos de qualidade de ensino, definidos como a variedade e quantidade mínimas, por aluno, de insumos indispensáveis ao desenvolvimento do processo de ensino-aprendizagem.

Entende-se que a análise teórica e documental aqui empreendida subsidia a discussão sobre o ensino e aprendizagem de conceitos na perspectiva do ensino desenvolvimental e que necessita ser difundida e aprofundada. Acredita-se que a discussão aqui apresentada, formada pelo recorte teórico que trata sobre o processo de formação de conceitos com fundamentação na teoria histórico-cultural, possa ser útil para repensar criticamente a formação e a prática dos professores, bem como os cursos de formação inicial de professores, uma vez que são estes profissionais que materializam o encontro entre os conteúdos do currículo e os alunos. A difusão do conteúdo preconizado nos documentos oficiais que tratam sobre as políticas de corte social, neste caso as políticas educacionais, também carece de ser entendido no âmbito da escola.

\section{Considerações Finais}

A atividade que promove o encontro entre o aluno e o conteúdo de ensino é realizada pelo professor quando este se propõe a estruturar os elementos que constituem a didática. A formação desse professor também é algo que tem grande peso em sua prática e em seu entendimento, se se considerar o referencial teórico que vai orientá-lo. Se há ausência de conhecimentos sólidos e aprofundados dos pressupostos teóricos e o conhecimento teórico e pedagógico a ser integrado aos conteúdos a serem ensinados, pode-se afirmar que está tangente uma frágil preparação pedagógica. Isso implica atentar para cursos de Pedagogia e de Licenciatura no que diz respeito ao aprofundamento das teorias pedagógicas e ao conteúdo de cada área do conhecimento. Esta fragilidade na preparação pedagógica acarreta um prejuízo no desenvolvimento dos alunos, uma vez que esse professor não tem domínio sobre como organizar o ensino do conteúdo a ser ensinado, de modo que o aluno aprenda os conceitos da ciência objeto de ensino.

Os resultados dessa investigação teórica e documental permitiram concluir que o ensino e a aprendizagem por meio da formação de conceitos, embora sejam muito mais promissores para o desenvolvimento intelectual dos alunos e resulte em formação de novas ações mentais correlatas ao conhecimento das áreas do conhecimento, não se mostram tão presentes na escola, por diversos fatores. Para a superação do ensino empírico é mister um amplo investimento em investigações, estudos e práticas de pesquisa, bem como práticas de ensino. Mas é necessária, sobretudo, uma revisão profundamente crítica da política de ensino, em todos os seus aspectos, que hoje está vigente em nosso país. Podemos afirmar que esta política tem permitido que o ensino continue sendo voltado apenas à formação do pensamento empírico dos estudantes, com prejuízos para uma verdadeira aprendizagem dos conceitos. Em outras palavras não envolve a aprendizagem de qualidade que é prescrita nos documentos oficiais e que é capaz de proporcionar ao aluno o "[...] pleno desenvolvimento da pessoa, seu preparo para o exercício da cidadania [...].” (BRASIL, 1988). 


\section{REFERÊNCIAS}

BRASIL. Lei no 9394, de 20 de dezembro de 1996. Estabelece as diretrizes e bases da educação nacional. Diário Oficial da União. Brasília, 21 dez., 1996. Disponível em http://www.planalto.gov.br/ccivil_03/LEIS/L9394.htm. Acesso em 20/05/2015.

BRASIL. Constituição da República Federativa do Brasil. Brasília, DF: Senado Federal, 1988.

DAVYDOV, V. V. Il problema della generalizzzione e del concetto nella teoria di Vygotsky. Tradução de José Carlos Libâneo. Studi di Psicologiadell'Educazione, vol. 1, 2, 3, Roma, 1997.

DAVYDOV, V. V. Problems of developmental teaching - The experience of theoretical and experimental psychological research. Soviet Education, v. XXX, n. 8, ago. 1988.

FREITAS, R. A. M. M. Organização do ensino na escola contemporânea - contribuições da Teoria Histórico-Cultural. Colóquio Internacional Educação e Contemporaneidade, 2009, UFS Campus Itabaiana - Se. Anais. III COLÓQUIO INTERNACIONAL EDUCAÇÃO E CONTEMPORANEIDADE, 2009.

LEONTIEV, A. N. El marxismo e la ciencia psicológica. In: LEONTIEV, A. N. Actividad, conciencia, personalidad. Ciudad de la Habana: Editorial Pueblo y Educación, 1983.

LEONTIEV, A. N. Uma contribuição à teoria do desenvolvimento da psique infantil. In: Vygotsky, Luria, Leontiev. Linguagem, desenvolvimento e aprendizagem. São Paulo: Ícone, 1988.

LOMPSCHER, J. Learning activity and its formation: ascending from the abstract to the concret. HEDEGAARD, M.; LOMPSCHER, J. (Eds.). Learning activity and development. Aarhus (Dinamarca): Aarhus University Press, 1999. p. 139-166.

SAVIANI, Dermeval. Entrevista Demerval Saviani: educação é a força motriz da economia. Disponível em http://www.contee.org.br/noticias/educacao/nedu752.asp. Acessado em $\underline{26 / 10 / 2015}$.

VYGOTSKY, L. A formação social da mente: o desenvolvimento dos processos psicológicos superiores. São Paulo: Martins Fontes, 1998. 